\title{
Study on Mechanical Properties and Fractal Characterization of Concrete under Impact Load
}

\author{
Zhenfu CHEN \\ Key laboratory of Treatment of Disasters in Engineering \\ University of South China \\ Hengyang, China \\ e-mail: Czf37@163.com \\ Yuanchu GAN \\ Key laboratory of Treatment of Disasters in Engineering \\ University of South China \\ Hengyang, China \\ e-mail: gan_yuanchu@126.com
}

\author{
Yiyan ZHONG \\ School of Civil Engineering \\ University of South China \\ Hengyang, China \\ e-mail: Yiyan_Zhong@qq.com
}

\begin{abstract}
In order to research the mechanical properties of concrete under impact load, a splitting tensile test of concrete cubes was carried out under the impact load by using the drop test machine. A high-speed camera was used in test to record the crack development process of each specimen. According to box dimension algorithm thoughts and principles of digital image storage, simple algorithms designed based on Matlab computing capabilities of concrete specimens damage crack fractal dimension of under the impact loads. The results show: with the increase of drop height and quality, loading rate, peak load and strain rate has significant strain rate, the crack fractal dimension values are increasing gradually; the surface crack distribution and development process of damaged concrete exhibit fractal properties, the fracture fractal dimension of the specimen increases with time, and when it is under different impact conditions, the fractal dimension of the specimen increases with the increase of the impact load and the strain rate.
\end{abstract}

Keywords-concrete; impact load; strain rate effect; fractal dimension

\section{INTRODUCTION}

Concrete is widely used as a kind of engineering material in buildings. As a quasi-brittle material, concrete is prone to tensile failure. The study of concrete properties is of great significance to structural safety design and seismic design [12]. In addition to static load, concrete structures are inevitably subject to a series of dynamic loads such as earthquakes, explosions, shocks, and so on. Since the concrete is a typical rate-sensitive material, its mechanical properties and damage characteristics will change greatly under dynamic load, so it is very important to study the dynamic damage characteristics of concrete. In this paper, the splitting tensile test of concrete under different strain rate impact conditions is carried out by changing the height and quality of the drop hammer, besides, the shock process of each specimen is recorded by a high-speed video camera. It is of theoretical and practical significance to study the damage and fracture process and the failure mesocharacteristics of the structure under different strain rates, after getting the impact force-time curve, strain-time curve and failure mode of each specimen.

Mandelbrot B B created the fractal geometry in the mid1970s [3], in which he pointed out that many disordered systems in nature have fractal characteristics. Fractal is a scattered but very fine structure of the pattern. If you zoom in, you'll see recurring details, so similar structures exist at all scales. It has been proved [4-6] that the fracture growth and distribution of concrete structure has fractal characteristics, the fractal dimension can be used as a fractal factor to measure the degree of structural damage and can be used to quantitatively describe the surface crack distribution. The fractal dimension of structure damage crack is related to such factors as the size and material strength of the specimen [7], mainly reflects the tortuous degree of crack and the density of crack distribution. Based on this background, the paper [8] combined with the digital image analysis technology and box-dimensional algorithm thought to design a simple algorithm of digital image box dimension based on Matlab function, which can be used to simulate the box dimensions of surface cracks of the concrete specimen under impact load. Therefore, it is helpful to discuss the inherent law between the dynamic load and damage crack of concrete under impact load by using fractal dimension as a quantitative parameter to characterize the failure degree of concrete and calculate the fractal dimension of concrete surface crack.

\section{Testing CONTENTS AND Methods}

\section{A. Test Material Preparation}

The test material used 32.5 composite portland cement, coarse aggregate for the continuous gravel pebbles which the maximum particle size of $25 \mathrm{~mm}$. Fine aggregate for the natural river sand, measured by the fineness modulus of 2.61, belonging to the sand. The concrete mix design is shown in 
Table 1. And according to GB / T 50081-2002 "ordinary concrete mechanical properties test method standard", the size of splitting tensile test specimen is $150 \mathrm{~mm} \times 150 \mathrm{~mm} \times 150 \mathrm{~mm}$, and its cube compressive strength is $36.2 \mathrm{MPa}$ after 28 days of standard curing.

TABLE I. CONCRETE Mix Design (UNIT: KG/M³)

\begin{tabular}{ccccc}
\hline $\begin{array}{c}\text { Theoretical } \\
\text { unit weigh }\end{array}$ & Water & Cement & Sand & Rock \\
\hline 2400 & 185 & 429 & 536 & 1250 \\
\hline
\end{tabular}

\section{B. Test Equipment}

The test was carried out on a drop hammer test machine at the Structural Laboratory of the School of Civil Engineering, University of South China. Test machine basic technical indicators are as follows: the maximum hammer height is $5 \mathrm{~m}$, and the drop hammer quality range of $70 \mathrm{~kg}$ to $200 \mathrm{~kg}$. In this test, an aluminum hammer having a hammer mass of $3 \mathrm{~kg}$ was used. The test was carried out by lifting the heavy hammer to a certain height and free falling to carry out dynamic impact on the concrete specimen. The dynamic splitting tensile test at different strain rates was carried out by changing the drop height and quality.

\section{TEST RESULTS AND ANALYSIS}

In order to study the strain rate effect of concrete, as well as the stress and deformation characteristics of concrete specimens under impact load, the test recorded the impact force-time curve and strain-time curve of different drop height and quality, and also recorded the failure process and mode of the specimens by a high-speed camera. To ensure the repeatability of the experiment, each type of test using only one variable, and each shock was kept in the same parameters and experimental conditions except for the variables. Each group of experiment repeated three times, the results take the average of three groups of tests.

TABLE II. IMPACt TEST OF DIFFERENT DROP HEIGHT

\begin{tabular}{ccccccc}
\hline No. & $\begin{array}{c}\text { Quality } \\
(\mathbf{k g})\end{array}$ & $\begin{array}{c}\text { Height } \\
(\mathbf{m})\end{array}$ & $\begin{array}{c}\text { Peak Force } \\
(\mathbf{K N})\end{array}$ & $\begin{array}{c}\text { Moment of Peak } \\
\text { Force }(\mathbf{m s})\end{array}$ & $\begin{array}{c}\text { Impact Time } \\
(\mathbf{m s})\end{array}$ & $\begin{array}{c}\text { Ultimate Tensile } \\
\text { Strain }\left(\boldsymbol{\varepsilon}_{\mathbf{m a x}} \mathbf{1} \mathbf{1 0}^{-6}\right)\end{array}$ \\
\hline D8005-1 & 80 & 0.5 & 71.0 & 0.74 & 1.60 & -178.8 \\
D8005-2 & 80 & 0.5 & 71.7 & 0.74 & 1.62 & -156.3 \\
D8005-3 & 80 & 0.5 & 70.5 & 0.71 & 1.58 & -190.3 \\
D8007-1 & 80 & 0.7 & 84.8 & 0.60 & 1.55 & -373.2 \\
D8007-2 & 80 & 0.7 & 88.2 & 0.69 & 1.45 & -395.8 \\
D8007-3 & 80 & 0.7 & 82.8 & 0.56 & 1.45 & -350.1 \\
D8009-1 & 80 & 0.9 & 96.6 & 0.56 & 1.45 & -203.7 \\
D8009-2 & 80 & 0.9 & 92.5 & 0.50 & 1.47 & -216.2 \\
D8009-3 & 80 & 0.9 & 92.3 & 0.54 & -197.7 \\
\hline
\end{tabular}
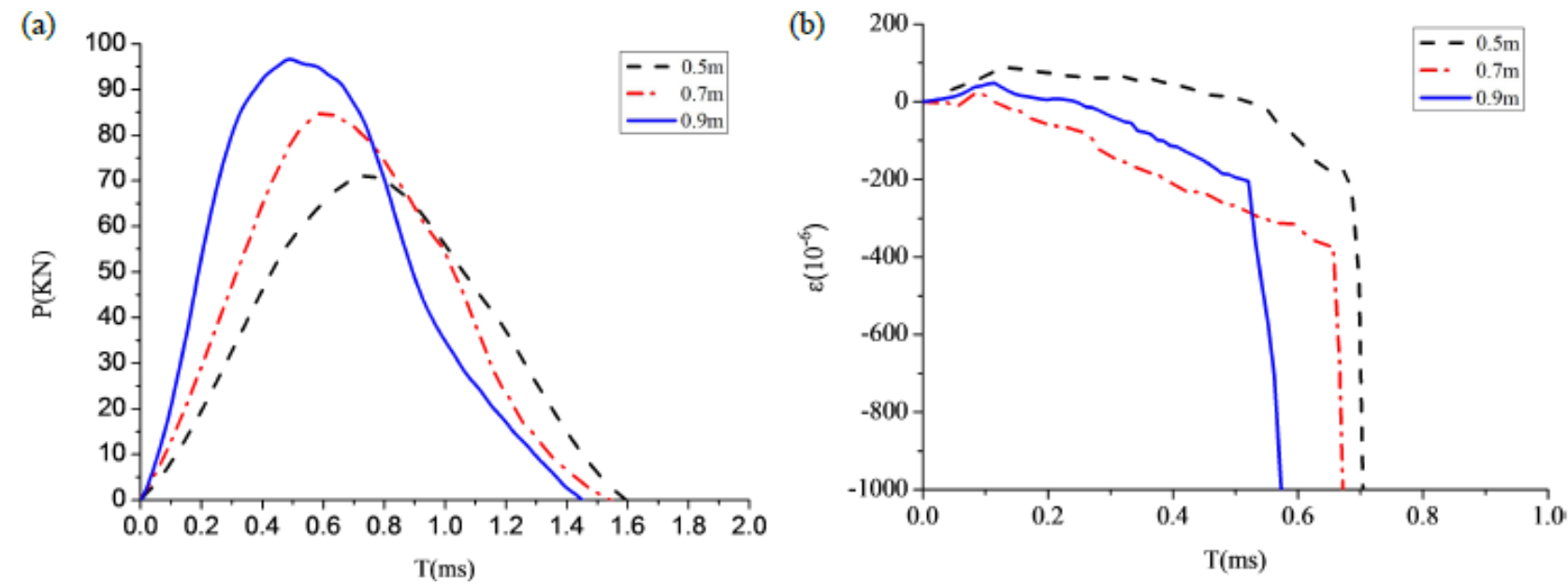

Figure 1. The impact force and lateral tensile strain histories in cases with varying drop heights when the drop quality is $80 \mathrm{~kg}$,(a) impact force, (b) lateral tensile strain 


\section{A. Study on the Impact Law of Different Drop Height}

In order to ensure the consistency of the quality, each test to take the drop quality of $80 \mathrm{~kg}$, three groups of concrete specimens impact test was carried out with drop height of $0.5 \mathrm{~m}, 0.7 \mathrm{~m}$ and $0.9 \mathrm{~m}$ respectively. The experimental results are summarized in Table 2, the impact force and lateral tensile strain time-history curves are shown in Figure 1, The curve data in the figure is the average result of each group of tests, the impact force and strain of the concrete are all positive under compression.

From the table data can be found, when the quality of the drop hammer is constant, with the falling hammer drop height increases, the peak value of the impact force increased significantly, and increased about $15 \%$. The loading and unloading slope of the force-time curve becomes steeper, the load rate becomes larger, and the action time of the impact force is slightly shortened.
In this experiment, concrete specimens under the impact of load splitting failure occurred. The tensile strain increases slowly before reaching the tensile strength, and the longitudinal cracks begin to appear on the surface of the specimen. As the crack develops, the tensile strain increases rapidly, until the crack penetrates, the strain piece breaks, and the specimen is completely split.

The values of the ultimate tensile strain in Table 2 are the strain values at the time of complete cleavage of the concrete specimen and can be seen in Fig. 2 as the corresponding strain value at the inflection point of the curve in the tensile strain time curve.

From the table data and figure can be found, when the quality of the drop hammer is constant, with the increase in the height of the drop, the concrete crack time is relatively early, the strain rate increases. The ultimate tensile strain is close to 190 microstrain at $0.5 \mathrm{~m}$ and $0.9 \mathrm{~m}$, while the ultimate tensile strain at $370 \mathrm{~m}$ is 370 tensile strain.

TABLE III. IMPACT TEST OF DIFFERENT DROP QUALITY

\begin{tabular}{ccccccc}
\hline No. & $\begin{array}{c}\text { Quality } \\
(\mathbf{k g})\end{array}$ & $\begin{array}{c}\text { Height } \\
(\mathbf{m})\end{array}$ & $\begin{array}{c}\text { Peak Force } \\
(\mathbf{K N})\end{array}$ & $\begin{array}{c}\text { Moment of Peak } \\
\text { Force }(\mathbf{m s})\end{array}$ & $\begin{array}{c}\text { Impact Time } \\
(\mathbf{m s})\end{array}$ & $\begin{array}{c}\text { Ultimate Tensile } \\
\text { Strain }\left(\boldsymbol{\varepsilon}_{\mathbf{m a x}} / \mathbf{1 0} \mathbf{0}^{-6}\right)\end{array}$ \\
\hline D7007-1 & 70 & 0.7 & 86.0 & 0.54 & 1.42 & -442.9 \\
D7007-2 & 70 & 0.7 & 85.8 & 0.49 & 1.45 & -356.3 \\
D7007-3 & 70 & 0.7 & 88.2 & 0.60 & 1.48 & -490.3 \\
D8007-1 & 80 & 0.7 & 84.8 & 0.59 & 1.55 & -373.2 \\
D8007-2 & 80 & 0.7 & 88.2 & 0.72 & 1.45 & -395.8 \\
D8007-3 & 80 & 0.7 & 82.8 & 0.46 & 1.51 & -350.1 \\
D9007-1 & 90 & 0.7 & 85.4 & 0.69 & 1.60 & -291.0 \\
D9007-2 & 90 & 0.7 & 88.2 & 0.72 & 1.58 & -316.2 \\
D9007-3 & 90 & 0.7 & 85.0 & 0.70 & 1.59 & -297.7 \\
\hline
\end{tabular}
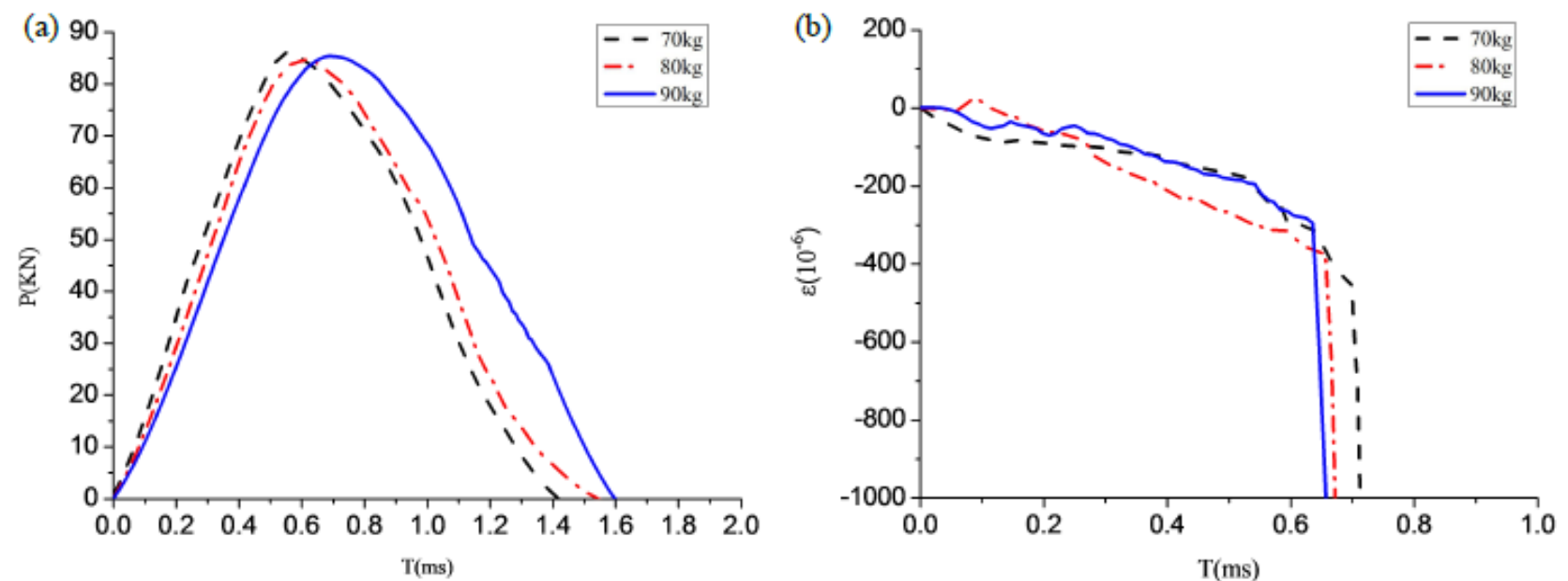

Figure 2. The impact force and lateral tensile strain histories in cases with varying drop qualities when the drop height is $0.7 \mathrm{~m}$, (a) impact force, (b) lateral tensile strain 


\section{B. Study on the Impact Law of Different Drop Weight}

In order to ensure the consistency of the height, each test to take the drop height of $0.7 \mathrm{~m}$, three groups of concrete specimens impact test was carried out with drop quality of $70 \mathrm{~kg}, 80 \mathrm{~kg}$ and $90 \mathrm{~kg}$ respectively. The experimental results are summarized in Table 3; the impact force and lateral tensile strain time-history curves are shown in Fig.2.

From the data in Table 3 and Fig.2, it can be found that when the height of the drop hammer is constant, with the falling hammer drop quality increases, the peak value of the impact force of the specimen is almost equal. The forcetime curve gradually slows down, the peak value of load exhibits hysteresis, the loading rate decreases, and the action time of impact force increases slightly. The value of ultimate tensile strain is gradually reduced, the initiation time of concrete is slightly ahead of time, and the splitting speed is accelerated.

\section{FRACTAL CHARACTERISTICS ANALYSIS}

The fractal dimension of the box-counting dimension is determined in this study. According to the box dimension algorithm and digital image storage principle, the digital image box dimension calculation program based on Matlab is designed, and a simple algorithm for the dimension of digital image box is established, which provides a method for calculating the dimension of cracks on the surface of concrete.

The experimental results show that the fracture of concrete has good fractal characteristics under impact load, and the fractal dimension can be used as the description parameter of damage degree of concrete.

It can be seen from Fig.3, The fracture fractal dimension of the specimen increases with time under the same impact condition, and when it is under different impact conditions, the fracture fractal dimension of the specimen increases with the increase of the impact load and the strain rate.

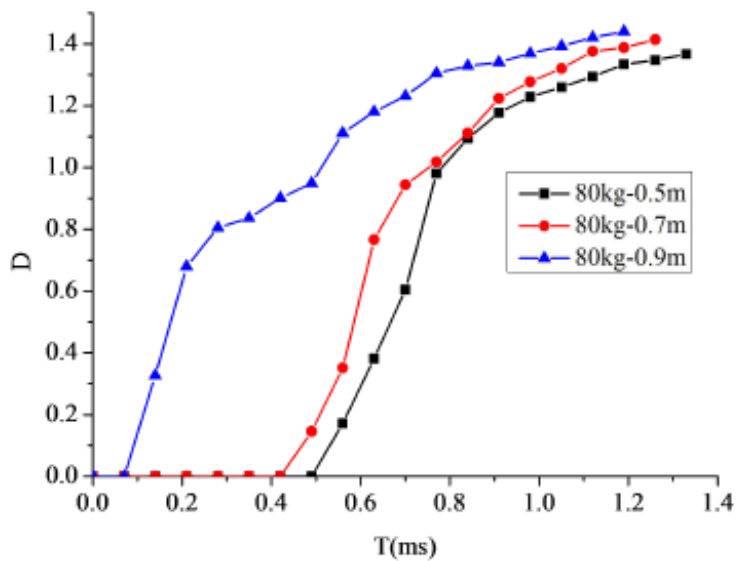

Figure 3. Fractal dimension curve of crack under different impact

\section{CONCLUSION}

The following conclusions can be obtained by measuring the mechanical strength, deformation and fractal properties of concrete specimens under impact loading:

(1) Under the impact load, with the falling hammer drop height increases, the impact force peak value and load rate of the specimen increase gradually, the impact time is slightly shorter, and the concrete crack time is relatively early, the strain rate increases.

(2) Under the impact load, with the increase of the quality of the drop hammer, the action time of the impact force increases slightly, the ultimate tensile strain decreases gradually, and the concrete initiation time is slightly ahead of time.

(3) Fracture of concrete has a good fractal characteristics, fractal dimension is a quantitative parameter to characterize the degree of concrete damage, which reflects the damage evolution characteristics of concrete. Fractal dimension can be used as the description parameter of damage degree of concrete. The fracture fractal dimension of the specimen increases with time under the same impact condition, and when it is under different impact conditions, the fracture fractal dimension of the specimen increases with the increase of the impact load and the strain rate.

\section{ACKNOWLEDGMENTS}

This work was supported by the National Natural Science Foundation of China (Grant No. 51678286, 51479098) and the Natural Science Foundation of Hunan Province (Grant No. 2016JJ2107) and the Initiative Scientific Research Program of Education Department of Hunan (Grant No. 13A082) and the Initiative Scientific Research Program of University of south china.

\section{REFERENCES}

[1] ZHANG Chuhan, "Discrete-Contact-Fracture Analysis of Rock Concrete," Chinese Journal of Rock Mechanics and Engineering, Vol. 27, Feb. 2008 pp. 217-235.

[2] LIN Gao, CHEN Jianyun, "Seismic Safety Evaluation of Concrete Dam," vol. 2, Feb. 2001, pp.8-15, doi: 10.13243/j.cnki.slxb.2001.02. 002.

[3] Mandelbrot B B.Fractal geometry of nature .W H Freeman, 1982.

[4] CAO Maosen, REN Qingwen, ZHAI Ailiang, ZHANG Jing, "Experimental Study on Fractal Characterization in Damages of Concrete Structures," Rock and Soil Mechanics, Vol.26, Oct. 2005, pp. 1570-1574, doi: 10.16285/j.rsm. 2005. 10. 009.

[5] Li Shibin, Tang Hongwei, Zhu Cimian, "Fractal Behavior of Reinforced Concrete Structures Damage Evolution," Journal of Shijiazhuang Railway Institute, Vol.19, Mar. 2006, pp. 52-57, doi: 10.13319/j.cnki.sjztddxxbzrb.2006.01.014.

[6] QIU Haoqun, KE Guojun, XIE Yanjun, "Research on the Mechanical Properties of Waste Glass Concrete and Fractal Evaluation under Impact Loading," Concrete, NO.2, 2016, PP, 110-113.

[7] ZHOU Kerong, XIAO Xiaosong, WU Xiaohan, "Fractal Behavior of Size Effect of Concrete Cubic Compressive Strength," Journal of Fuzhou University (Natural Science), Vol .24, Sep. 1996, pp. 63-68.

[8] ZHU Wenhua, LI Jianxiong, ZHANG Mingzhong, "2D Digital Image Box-counting Dimension Calculational Method of Cracks on Damaged Concrete," Journal of Wuhan University of Technology, vol. 30, Jun. 2008, pp. 60-62. 